\title{
Public Health, Social and Economic Burdens Caused by Zika and Chikungunya Viruses in Latin America
}

\author{
RL Thomasini*1,2 and FSM Pereira ${ }^{2}$ \\ ${ }^{1}$ Multicentric Program of Postgraduate in Physiological Sciences, Federal University of Jequitinhonha and Mucuri Valleys, Brazil
}

${ }^{2}$ Center for the Study of Inflammatory and Infectious Pathologies (NEPii), Faculty of Medicine of Diamantina-FAMED, Federal University of Jequitinhonha and Mucuri Valleys, Brazil

Received: 眥: December 10, 2018; Published: 眥: December 19, 2018

*Corresponding author: RL Thomasini, Multicentric Program of Postgraduate in Physiological Sciences (PMPGCF), Diamantina, Brazil

\section{Opinion}

The Zika and Chikungunya viruses have been introduced in Latin America practically at the same time and probably during FIFA's World Cup (football) which occurred in Brazil in 2014's. A large number of people from all over of the world have travelled to South America due to the games and they did not stay strictly in Brazil and/or countries bordering Brazil. The absence of previously circulation of both viruses in Latin America led to a complete lack of immunization in the population which it was worsened due to the fact that the vaccines do not exist. There is an endemic common vector for arboviruses called Aedes aegypti which is largely known by its capacity to transmit Dengue virus, and in the past also enrolled in the transmission of urban yellow fever. The combination of these factors played a crucial role in the uncontrolled dissemination of both viruses. Moreover, the unfamiliarity with the clinical features of the infection, a relative similarity with Dengue and unavailability of laboratory methods for diagnosis in that time, turned difficult to monitor the spreading, severity and number of cases.

Posteriorly, the Zika virus was suspected to be a cause of microcephaly in children whose mothers have been infected during pregnancy. Although the true enrolment and mechanism which the virus causes that effect in the foetus remain under investigation, the relationship between virus and microcephaly seems to be clear based on observational data related by physicians in practice. Chikungunya virus has proven to cause persistent symptoms especially arthritis leading to physical disabilities and reducing the life quality of patients for months or years. Children born with microcephaly will need medical, physiotherapeutic and psychological care during their lifetime and it will lead to a substantial impact on the public health system. Moreover, families which have a child with microcephaly are immeasurably economically and psychologically affected leading to a heavy social impact for these families. Also, patients infected by Chikungunya virus remain out of their jobs due to physical disabilities leading to economic impact not only for the patient but also to the general economy. In addition, the public health system will be also affected due to the fact that these patients will also need medical, physiotherapeutic (and sometimes psychological) assistance for an unpredictable time.

The severity of dengue and yellow fever is clearly higher then Zika and Chikungunya at the time of infection. Yellow fever can cause death in a substantial part of patients and dengue can present a severe form of disease including a haemorrhagic feature. However, after the infection has been cleared, the patients with yellow fever or dengue recovery fine. Differently, Chikungunya has not so severe feature at the time of infection but the recovery is dragged compared with yellow fever or dengue. Zika causes also not a severe disease at the time of infection but can lead to microcephaly as it was discussed above. The control of the vector (A. aegypti) has shown not efficient due to different factors. The impenetrability of educational projects regarding the vector control, resistance to insecticide, higher propagation of mosquitoes in the rainy seasons and difficult to public agent enrolled in the larvae control to access the dwelling-places are among the most important factor for the inefficiency of vector control. However, due to the lack of vaccines, the control vector remains the unique tool to avoid the spreading of these viruses. The notification of the occurrence of infected patients and reinforcement of control vector in that places where the viruses are circulating enhances the efficacy of the controlling.

The use of insect repellent seems to be the best way to avoid mosquitoes bites and virus transmission and it has been strongly 
advised, especially for pregnant women. The major preoccupation is a potential toxicity of insect repellent to the foetus. The icaridinbased products have been recommended by the World Health Organization and Center for Disease Control and Prevention (United States of America) based on its efficacy and safety to pregnant women and foetus. Although several manners to reduce the impact of the Zika and Chikungunya viruses in Latin America

\section{ISSN: 2574-1241}

DOI: 10.26717/BJSTR.2018.12.002242

RL Thomasini. Biomed J Sci \& Tech Res

CC (i) This work is licensed under Creative

Submission Link: https://biomedres.us/submit-manuscript.php have been used, it is mandatory to develop vaccines to protect against the infections especially due to the viruses could propagate to other areas around the world where the A. aegypti is endemic. Currently, it is clear that the epidemics of Zika and Chikungunya viruses caused a severe burden to public health, economy, and society in Latin America.

$\begin{array}{ll}\text { BIOMEDICAL } & \text { Assets of Publishing with us } \\ \text { RESEARCHES } & \text { - Global archiving of articles } \\ & \text { - Immediate, unrestricted online access } \\ & \text { - Rigorous Peer Review Process } \\ \end{array}$

